\title{
ACCESS TO INTERNET AS A HUMAN RIGHT - JUSTIFICATION AND COMPARATIVE STUDY
}

\begin{abstract}
This paper advances a human rights perspective to the understanding of internet access by viewing it through a comparative lens with reference to countries in Europe, and the USA, India, and China. The question that is explored is: does internet access warrant recognition as a stand-alone human right, or is it sufficient that access is so bound up with one or more existing rights that formal recognition is unnecessary? Through this paper an effort has been made to analyse whether having a right to internet access as a human right is possible and to argue for the need to recognise such a right given the importance such a right holds, as can be seen especially during the ongoing pandemic when every aspect of life has been shifted to the online mode.
\end{abstract}

\section{Keywords}

Internet access - international human rights law - comparative perspective - state responsibility and COVID 19

\section{INTRODUCTION}

One of the foremost specialists who advocated for the right to internet access as a human right was Viviane Reding who was the Commissioner

\footnotetext{
* Lecturer, OP Jindal Global University, Sonipat, India, e-mail: amehrotra@jgu.edu.in.
} 
of the European Union. ${ }^{1}$ It is believed under international law that freedom of access to information is the foundation upon which all the other rights such as free expression depend. The first mention of the ideals and values of cyberspace such as freedom, liberty, and its uniqueness came through the First Generation of internet thinkers also known as the cyber libertarians ${ }^{2}$ such as John Perry Barlow. These thinkers suggested various ways to protect cyberspace such as self-governance and autonomy in cyberspace. However, a new order of information and communication developed within the third world countries that supported state regulation on access to information and opposed the free flow of information used to secure social, political, and economic rights. The US and many western countries cited the threat to free access to information and freedom of expression as reasons for their opposition to state regulation of cyber space. Thus, the concept of "Digital divide" came into being, referring to the difference between the developed and developing countries in terms of access to the internet, thus in turn affecting the free flow of information. As a result, the United Nations adopted Resolution number $A / H R C / 2 / 220$ on $27^{\text {th }}$ June 2016 which dealt with the promotion, protection and exercise of rights over the internet. Through the resolution, the UN condemns all measures that deliberatively prevent or disrupt access to the internet.

At an international level, there has always been a debate among the academics and the lawyers regarding freedom of access to the internet and legal forms of control. This debate recognises that on the one hand there are needs like self-determination and social goals for the individuals and people for which internet access assumes significance, on the other the need to protect privacy and national interests through control, censorship, and surveillance.

In practice, the states protect privacy and the national interest by imposing internet shutdowns that amount to deliberate prevention or disruption of access or dissemination of information. There exist various forms through which it is implemented such as blocking or throttling of

${ }^{1}$ H. Liu, Y. Yan, "Interpretation of the Concept of the Right to Internet Access from the Perspective of International Law", J. HUM. RTS., 2016, Issue 15, p. 140.

2 J. W. Penney, "Internet Access Rights : A Brief History and Intellectual Origins", Wm. Mitchell L. Rev., 2011, Vol. 10. 
mobile communications, websites, or social media and messaging applications. ${ }^{3}$ Seen in this light, the concept of intentional disconnections by the government could be understood in three parts. ${ }^{4}$ Firstly, the aspect of the intention behind imposing the lockdown by the government or the internet Service providers, then the definition of disruption of internet services as discussed above, and finally the focus on the specific location or population where the disruption takes place.

Interestingly, the Constitution of the International Telecommunication Union (ITU) provides legal grounds to justify internet shutdowns such as the right of the ITU member states to block telecommunication services ${ }^{5}$ under Articles 34 and 35 of its Constitution that reserves the right of the member states to cut off, in accordance with their national law, any other private telecommunications for reasons of national security; public order, or decency. Additionally, the member states may also be able to restrict access to the internet through the suspension of services by notifying the Secretary-General of the UN as well as other member states about the same.

In this light, the article is divided into four parts: the first part focuses on the concept of internet access; the second part deals with internet access as a social right, while the third part examines and evaluates internet access as a human right, and finally, the fourth part reflects upon the practices regarding internet access around the world.

\section{CONCEPT OF INTERNET ACCESS}

According to the first-generation cyber libertarians who analysed, predicted, and prescribed the interrelation between law and the internet, there exist three phases through which the development of the law could be traced. These phases deal with the absence of law governing cyberspace; internet as a separate jurisdiction, and finally the emergence of laws

${ }^{3}$ UNHRC, "Report of the Special Rapporteur to the General Assembly on the Freedom of Opinion and Expression in the Digital Age" A/HR/C/35/22, 2017.

${ }^{4}$ B. Wagner, "Understanding Internet Shutdowns: A Case Study from Pakistan", International Journal of Communication, 2018, Vol. 12, p. 3918.

${ }^{5}$ M. Land, "Toward an international law of the Internet", HARV. INT'L LJ, 2013, Vol. 54, p. 393. 
governing cyberspace based on well-established legal standards. However, there remain concerns as to whether the proliferation and flourishing of rights and covenants is helping in achieving the higher protection or resulting in decreased protection. ${ }^{6}$

In this respect, the report of the UN Special Rapporteur Frank La Rue on the promotion and protection of the right to freedom of opinion and expression assumes significance as it focused on the challenges encountered in ensuring the right of all individuals to seek, receive, and impart information and ideas of all kinds through the internet. ${ }^{7}$ Historically, internet access has been recognised under international law through Article 19 (2) of the International Covenant on Civil and Political Rights (ICCPR) that recognises the right to hold opinions without interference and the right to freedom of expression either orally; in writing or in print, in the form of art, or through any other medium. Thus, the principles under Article 19 ICCPR play an integral role in regulating the right to access the internet at both the national and international level. ${ }^{8}$

What needs to be understood is that Article 19 establishes the individuals as active participants and not passive recipients of information owing to the acts of receiving, seeking, and imparting information that are inherently interactive in nature. ${ }^{9}$ Further, it also provides guidelines regarding the term 'media' which facilitate the process of connection between the individuals that are in line with the General Comment 34 on freedom of opinion and expression and states the following:

"Paragraph 2 protects all forms of expression and the means of their dissemination. Such forms include spoken, written, and sign language, and such non-verbal expressions as images and objects of art. Means of expression include books, newspapers, pamphlets, posters, banners, and legal

6 O. Pullicino, "Right to Internet Access: Quid Iuris?" The Cambridge Handbook on New Human Rights, 2019.

7 UNHRC, "Report of the Special Rapporteur on the promotion and protection of the right to freedom of opinion and expression", A/HRC/23/40, 2003.

${ }^{8}$ Land, supra note 5, p. 393.

${ }^{9}$ M. Nowak, UN Covenant on Civil and Political Rights: CCPR Commentary, 2nd edn, Kehl: N.P. Engel, 2005, passim. 
submissions. They include all forms of audio-visual as well as electronic and Internet-based modes of expression". ${ }^{10}$

The European Court of Human Rights (ECtHR) has dealt with cases concerning Article 10 of the European Convention on Human Rights (ECHR) that is framed similarly to Article 19 ICCPR. Under Article 10 of ECHR, the right to freedom of expression has been recognised and includes the freedom to hold opinions and receive and impart information and ideas without interference and regardless of frontiers and, as well, states the restriction that can be imposed in the interests of national security; protection of health and morals; reputation or rights of others as is also stated under Article 19 ICCPR. There are several cases where the ECtHR has dealt with Article 10 which provide useful guidance on the scope of the right. To illustrate, in the case of Autronic AG v. Switzerland ${ }^{11}$ the ECtHR had expressly stated that the scope of Article 10 is not limited to content of information, but also applies to the means of transmission or reception owing to the fact that any restriction imposed on the means also interferes with the right to receive and impart information. Similarly, in 2012, the ECtHR, in the case of Ahmet Yildirim v. Turkey ${ }^{12}$ found that a restriction imposed on accessing internet violated Article 10. In this case a criminal court of first instance had ordered the blocking of an internet site, because its owner had been accused of insulting the memory of Atatürk who is considered the father of Turkey. Consequently, the owner was unable to access his own site despite discontinuation of proceedings against him. The ECtHR stated that the Turkish law does not permit blocking of all means of access, hence, the measures taken by the criminal court were arbitrary and violated Article 10 of the Convention.

${ }^{10}$ HRC, "General Comment No. 34: Article 19: Freedoms of opinion and expression", 12.9.2011, CCPR/C/GC/34, https://www.refworld.org/docid/4ed34b562.html [last accessed 17.6.2021].

11 Autronic AG v. Switzerland, Application no.12726/87, Judgment of 22.5.1990.

12 Ahmet Yildirim v.Turkey, Application no. 3111/10, Judgment of 18.12.2012. 


\section{INTERNET ACCESS AS ASOCIAL RIGHT}

During the Bucharest Declaration of the First World Summit on Information Society, the idea of internet access as a social right was discussed as follows:

"Where all persons, without distinction of any kind, exercise their right to freedom of opinion and expression, including freedom to hold opinions without interference and to seek, receive and impart information and ideas through any media and regardless of the frontiers". ${ }^{13}$

In simple terms, social rights include a whole range of rights, from rights ensuring economic welfare and security to the right that ensures participation in social and political affairs, and most importantly, the ability to live a dignified life as per the standard prevailing in the society However, there exist different perspectives on recognizing internet access as a social right. On the one hand those who adopt a neoliberal perspective despise the egalitarian declaration of rights to social resources. Moreover, the neoliberals argue for governments' role in facilitating open and competitive markets. ${ }^{14}$ On the other side exists the socialist perspective that argues for equal opportunity for all to participate in society. It demands the state's affirmative action to create or secure those substantive resources that individuals need to lead dignified and independent lives. Thus, the concept of universality is the basis upon which the socialists argue for equality and social justice that most of the democracies around the world uphold.

It cannot be overemphasised that the absence of having access to internet leads to a 'digital divide' between those who are online and use the net and those who do not especially in the ongoing pandemic. These divides exist across racial, economic, political, gender, language, and geographic lines. As a result, the marginalised groups of any given society remain even more marginalised more markedly in the developing

13 J. Berman, D. J. Witzner,"Technology and Democracy”, Soc. Res., 1997, Issue 64, p. 1313, 1314-15.

${ }^{14}$ T. Oyedemi, "Internet access as a citizen's right? Citizenship in the digital age", Citizenship Studies, 2015, Vol. 19, Issue 3-4, p. 450-464. 
countries. By ensuring internet access such groups can obtain information, assert their rights, and participate in public debates concerning social, economic, and political changes to improve their situation. It is widely accepted that if internet access was recognised as a positive right like many other rights under the International Covenant on Economic, Social and Cultural Rights (ICESCR), the governments would be placed under an affirmative obligation to ensure that all citizens enjoyed access, or a certain kind of access to the internet, such as putting in place the necessary infrastructure for internet connectivity, resource commitments, and public and private sector collaboration. In this regard, guidance can be sought from the United Nations Convention on the Rights of the Child (UNCRC) that mandates the member states to ensure free and compulsory primary education to all children and to simultaneously develop different forms of secondary and higher education as per the capacity and needs of the respective member states under Article 28 of its Convention.

This view has been further strengthened by the fact that merely possessing a broadband connection does not allow people to exercise their right to internet access as it requires basic information skills. These skills entail the capacity of an internet user to find information online; to identify important issues, and be able to analyse the relevance of such information. ${ }^{15}$ However, these steps to ensure access to the internet have excluded certain groups. For example, in the US, the information literacy programmes have been adopted by the schools, but have failed to take into account the special case of African-American children living in underdeveloped areas. ${ }^{16}$ What this signifies is that the basic rights of human beings and citizens to communicate and participate in the social, cultural, and political spheres of a society need to be inculcated within the theoretical structure of access to technologies. ${ }^{17}$ This is because the individuals lacking access become socially disadvan-

${ }^{15}$ D. J. Leu et al., "Towards a Theory of New Literacies Emerging From the Internet and Other Information and Communication Technologies", Reading Research Quarterly, 2004, Issue 35, p. 108-127.

${ }^{16}$ L. A. Jackson, et al., "Race, Gender, and Information Technology Use: the New Digital Divide", Cyber Psychology and Behaviour, 2008, Issue 11, p. 437, 441.

17 D. Beland,"Insecurity, Citizenship, and Globalization”, Sociological Theory, Issue 23, p. 25-41. 
taged or excluded because they cannot obtain information or communicate. This leads to their social exclusion and arguably amounts to a human rights violation..$^{18}$ One thing is clear, if the right to internet access has to gain recognition, it has to be ensured by the efforts of governments of various countries which are not only restricted to providing access and non-interference in exercise of the right, but by the need to overcome the factors that lead to the digital divide prevailing within the countries.

\section{EXAMINATION AND EVALUATION OF INTERNET ACCESS AS A HUMAN RIGHT}

International Internet law may be defined as a framework within public international law that encompasses issues within civil law in the form of protecting personal rights over the internet, trade law that includes issues ranging from e-commerce to trademark protection, administrative law on cross border services being offered through the internet and the most challenging questions of criminal law and its enforcement beginning from the hacking of accounts and cyber-attacks against other countries. Generally, internet access finds a place in State party reports; Concluding Observations and General Comments that are drafted by various international bodies. ${ }^{19}$

Over the years, the international community has acknowledged the importance of the internet. For example, the UN Millennium Declaration includes ensuring that the benefits of Information and communication technologies (ICT) are available to all. ${ }^{20}$ Similarly, the idea that the internet can be a tool for advancing human rights has been picked up by the Group of eight (G8), as they have recognised arbitrary or indiscriminate

18 S. Park, “The United Nations Human Rights Council's Resolution on Protection of Freedom of Expression on the Internet as a First Step in Protecting Human Rights Online", N.C.J. Int'l L. E Com. Reg., 2012-2013, Issue 38, p. 1129.

19 M. L. Best, “Can the Internet be a Human Right?”, Palgrave Macmillan, 2000, p. 276.

${ }^{20}$ United Nations Millennium Declaration: resolution / adopted by the General Assembly, A/RES/55/2, 13.9.2000, available on undocs.org/en. 
censorship and the restriction of internet access as being inconsistent with international law. ${ }^{21}$

For instance, the Committee on Civil and Political Rights had expressed their concerns regarding Syria's blocking of access to the internet for political activists, and on the harassment of online journalists and human rights activists in Kyrgyzstan, Kuwait, Argentina, Gabon, and Peru. Similarly, the Committee on the Rights of the Child had raised concern regarding sexual exploitation; child trafficking; pornography, and harmful material accessible to children over the internet in countries like Monaco; Croatia; Greece; Costa Rica; Norway; Micronesia, and Japan..$^{22}$ In essence, the recommendations made by these committees focus on making people aware; suggesting that states should legislate, enforce, and implement the necessary policies and programmes.

In recent years, the legal experts have started exploring the possibility of dealing with cases concerning access to the internet from a human rights perspective. Beitz ${ }_{r}^{23}$ who was a Professor of Politics at Princeton University, was of the view that if having access to internet contributes to significant issues and protects interests, then there exist reasons to view it as a category of human rights. His approach is based on both the basic interest and the political role of a right in the contemporary human rights practice. Just to recap, a plausible justification for something to be part of human rights doctrine should incorporate three types of claims i.e. it is reasonable to recognise it; in the absence of its being protected there exists a probability that the municipal level institutions may endanger it, and it must not result in an undue burden for the right holders.

One such example where the municipal authorities violated the rights of its citizens in the absence of a democratic structure that resulted in grave violations was the Arab Spring. In 2011, the Egyptian government had imposed a shutdown of the internet to suppress dissenting voices of its citizens. This act was in direct contravention of the ICCPR. It was the Special Representative on the Promotion of the Right to Free-

${ }^{21}$ G 8 Declaration, "Renewed Commitment for Freedom and Democracy" G8 Summit of Deauville, 2011.

22 J. Kulesza, "International Internet law", Global Change, Peace \& Security, 2012, Issue 24, pp. 351-364.

${ }^{23}$ X. Wang, "Time to Think about Human Right to the Internet Access: A Beitz's Approach", Journal of Politics and Law, 2013, Issue 6, p. 67. 
dom of Opinion and Expression who emphasised the gravity of the situation and urged the government to restore freedom of expression and access to information for their citizens. ${ }^{24}$ Though this event happened a decade ago, the significance of having the right to internet access as a human right is clearly manifested through it.

In this respect, inspiration can be drawn from countries around the world that have either declared internet access as a human right or recognised it through municipal legislation as in the case of Estonia, which declared internet access to be a human right in under Article 44 of the Estonian Constitution. In addition, Finnish legislation specified the right of citizens to have Internet access, with Internet Service Providers required to offer specific broadband connection speeds. ${ }^{25}$ However, it needs to be taken into account that internet access cannot be instantly made available because of the issues that are specific to every member states, such as deficient electricity access, and this fact has been recognised by UN Special Rapporteurs. ${ }^{26}$ However, it has been clearly stated that all States should devote all possible resources to promote universal internet access. ${ }^{27}$

Considering all these factors, legal systems should incorporate internet access as human-right-based by adopting an international approach and establishing a neutral body. When it comes to adopting an international approach, the state needs to cooperate and develop partnerships with other jurisdictions as online issues are extraterritorial as explained by Lawrence Lessig, who presents an opinion that the social and legal powers in a state are not only governed through a constitution or legal text, but also by establishing an architecture. ${ }^{28}$

24 A. E. Cattle, “Digital Tahir Square: An Analysis of Human Rights and the Internet Examined Through The Lens of the Egyptian Arab Spring", Duke Journal of Comparative E International Law, 2016, Issue 26, pp. 417-449.

25 C. Ehret, "Finland Government Declares Legal Right to Broadband Internet Access", available at https://www.loc.gov/item/global-legal-monitor/2009-10-20/finland-broadband-access-to-be-a-legal-right/, [last accessed 7.9.2021].

${ }^{26}$ UN Special Rapporteur A. Hussain, "Report on the Promotion and Protection of the Right to Freedom of Opinion and Expression", E/CN 4/2002/75, 2000.

${ }^{27}$ UN Special Rapporteur A. Ligabo, "Report on the Promotion and Protection of the Right to Freedom of Opinion and Expression", A/HRC/4/27, 2007.

28 S. Tully, "A Human Right to Access the Internet - Problems and Prospects", Hum. Rts. L. Rev., 2014, Issue 14, p. 175. 


\section{INTERnet Access Practices Around the World}

It is a reasonable claim to make that the more enhanced the basic communications infrastructure of a country, the more likely this will be conducive to the assertion and manifestation of liberties and rights for the citizenry. ${ }^{29}$ In a democratic society, the states are the primary actors who have the authority to regulate the internet and develop an infrastructure for ensuring access to it. However, this is not always the case, especially in non-democratic states where internet access is susceptible to the power of the state. To further understand the practical situation, I refer to the practice of internet accessibility in the developed countries in Europe; the USA and reflect upon the conditions existing in developing countries like India and China.

In simple terms, the deployment of the internet has been shown to be a tool for such critical objectives as democracy and empowerment. For instance, researchers have shown that for factors like economic development, the level of internet connectivity is a strong predictor as it signifies the levels of democratic attainment. ${ }^{30}$ The common thread among these is the presence of a strong democratic political system that aims to safeguard the rights of its citizens by upholding the rule of law, respect for individual liberty, protection from oppressive state interference, and the defence of human rights.

The American doctrine that talks about the divide between self-regulation and state regulation. In the US, a market-centric approach has been adopted which facilitates innovation and growth with little or no regulation. Further, the US Department of Commerce has established a group that examines the accessibility issues and suggests ways to reduce them. Similarly, the Federal Communication Commission, which is a public body, has come up with regulations for the service providers with regard to unrestricted access and impartiality towards legal content. ${ }^{31}$ Under Reno

${ }^{29}$ C. Weare, "The Internet and Democracy : The Causal Links Between Technology and Politics", International Journal of Public Administration, 2006, Issue 25(5), pp. 659-691.

${ }^{30}$ Ibid., pp. 659-691.

${ }^{31}$ G. Minico, "Towards an Internet Bill of Rights", Loyola of Los Angeles International and Comparative Law Review, 2015, Vol. 37, No. 1, p. 1. 
v. ACLU, ${ }^{32}$ et al., the Supreme Court of the US ruled that the Internet is "a medium that, unlike radio i.e., a broadcast medium, receives full First Amendment protection." Thus, for someone publishing material on the Net, protections are as much in place as for those for publishing in a newspaper. According to the first amendment, Congress shall make no law respecting an establishment of religion, or prohibiting the free exercise thereof; or abridging the freedom of speech, or of the press; or the right of the people peaceably to assemble, and to petition the Government for a redress of grievances. Thus, material over the internet generally remains protected from censorship in the United States.

In Europe, however, the focus has been on content regulation i.e. the material being displayed to the users over the internet, protection of free speech, and the right to privacy. ${ }^{33}$ Moreover, Europe has taken a proactive approach regarding concerns related to privacy such as the European Union General Data Protection Regulation (GDPR) which shifts the responsibility for privacy and security to the service providers. ${ }^{34}$ The ECtHR through various case laws have time and again emphasised the significance of the internet as the principal means by which individuals exercise their right to freedom to receive and impart information and ideas. To illustrate, in the case of Cengiz and Others v. Turkey ${ }^{35}$ the ECtHR stated that the internet plays an important role in enhancing the public's access to news and facilitating the dissemination of information in general. In practice, Estonia, one of the European countries, has put in place a system called the eLaw system ("e-Oigus") $)^{36}$ that provides all citizens with free of charge up-to-date information on the laws prepared by the Estonian government from the conception stage to the presentation of a draft law. The citizens can express their opinion about the content of drafts and have the right to present ideas for initiating changes to the legislation.

32 Reno v. American Civil Liberties Union, 521 U.S. 844, Judgment of 1997.

33 A. Savin, "EU Internet Law", $2^{\text {nd }}$ edn, Edward Elgar Publishing, 2018, passim.

${ }^{34}$ N. Nilekani, “Data to the People : India's Inclusive Internet", Foreign Affairs, 2018, Vol. 97, p. 19.

35 Cengiz and others v. Turkey, Application No. 48226/10, Judgment of 12.12.2015.

36 J. Laffranque, "Access to, and Provision of, Legal Information in the Transition from Communism to Democracy in Estonia", Legal Information Management, 2006, Vol. 6, p. 113. 
With regard to India, it is imperative to state that the government has been in control of the systems that govern the internet, instead of leaving it to the private technological companies. In terms of the frequency of internet shutdowns, India holds the record for the greatest number of shutdowns in the world. ${ }^{37}$ These shutdowns are executed through the Temporary Suspension of Telecom Services (Public Emergency or Public Safety) Rules 2017, under which the competent authorities have a direct and express power to direct internet shutdowns. Additionally, the government can also impose a shutdown under section 5(2) of the Telegraph Act which authorises the government to detain telegraphs on the occurrence of a public emergency or in the interest of public safety.

One such example where internet shutdown took place in India was Kashmir, which is now a Union territory as the special status accorded to it under Article 370 of the Constitution was revoked on 5th August 2019, when millions of people awoke to find their internet, landlines, and mobile phones were no longer working. These steps were described as "precautionary measures" by the government in the interest of national security. Consequently, a writ petition was filed before the Supreme Court of India in the case Anuradha Bhasin and another versus Union of India and others ${ }^{38}$ that challenged the legitimacy of the discontinuation of mobile phone networks; internet services, and landline connectivity imposed in August 2019. The Supreme Court held that freedom of speech and expression and freedom to practice any profession or to carry any occupation; trade or business over the medium of internet enjoys constitutional protection under Article 19 (1) (a) and Article 19 (1) (g) of the Constitution that deal with the right to freedom of speech and expression and the right to carry on any trade or business respectively.

On similar lines, the Foundation for Media Professionals, which was an intervenor in Ms. Bhasin's petition, filed another petition before the Supreme Court of India under Article 32 of the Constitution that gives the right to move to Supreme Court for enforcement of fundamental

37 N. Nayak, "The legal disconnect: An analysis of India's Internet Shutdown Laws", Internet Freedom Foundation, 2018, available at https://internetfreedom.in/the-legal-disconnect-an-analysis-of-indias-internet-shutdown-laws/ [last accessed 7.9.2021].

38 Anuradha Bhasin v. Union of India (2019) SCC 1725. 
rights contained within Part III of the Constitution on 31 March 2020. This petition challenged the government's decision to deny $4 \mathrm{G}$ mobile internet access to the people of Jammu and Kashmir during a pandemic and nationwide lockdown when effective internet services were necessary to facilitate telemedicine, online learning, remote work, and virtual court hearings. ${ }^{39}$ Despite the multifaceted challenges faced during the COVID-19 pandemic and the nationwide lockdown, the Court once again declined to provide $4 \mathrm{G}$ mobile internet connection in Jammu and Kashmir.

Finally in China, the internet came into being in 1987, but gained significance from around 1995. It was in 1996 that the Chinese State Council promulgated the Interim Provisions governing the management of computer information networks that prohibited information regarding national security; state secrets; sexually suggestive material etc. An issue which is heavily debated in China is the digital divide among "haves" and "have nots" with varying internet access based on economic and regional lines. Such disparity exists between wealthy coastal residents and those residing in the inland countryside. It can further be explained through the definition given by the Organisation for Economic Co-operation and Development, according to which the gap is between the individuals, households, businesses, and geographic areas regarding both access to information and communication technologies. ${ }^{40}$ In recent times, the Reporters without Borders described China as one of the thirteen 'enemies of the internet. ${ }^{\prime 1}$ Thus, in China the focus has been on state control over accessing the internet.

39 D. Mukhopadhyay, A. Gupta, “Jammu \& Kashmir Internet Restrictions Cases: A Missed Opportunity to Redefine Fundamental Rights in the Digital Age", Indian J. Const. L., 2020, Vol. 9, p. 207.

${ }^{40}$ E. Harwit, "Spreading Telecommunications to Developing Areas in China: Telephones, the Internet and the Digital Divide", The China Quarterly, 2004, pp. 1010-1030.

${ }^{41}$ H. Zheng, "Regulating the Internet: China's Law and Practice", Beijing Law Review, 2013, Vol. 4, p. 37. 


\section{CONCLUSIONS}

As a facilitator for other rights, the rise of the right to internet access as a standalone human rights requires significant changes in the understanding of the purpose behind ensuring access to internet for the welfare of those belonging to the marginalised sections of society who lack the necessary infrastructure and information literacy to be able to connect with the rest of the world. Further, the internet shutdowns imposed throughout the rest of the world have acted as an obstacle in arguing for putting in place a right to internet access. Nonetheless, through positive measures adopted by countries that have been dealt with in this paper, they have been able to act as examples for other countries, while keeping in mind the socio-economic conditions of each. Through this paper, an attempt has been made to analyse the criteria through which any right is recognised as a human right in the context of internet access while at the same time referring to examples where absence of such a right has proved detrimental.

Overall, a holistic and inclusive approach involving enhanced cooperation and most importantly multi-sectoral collaboration within the countries and international organisations is the need of the hour to ensure the right to internet access. 
